\title{
O060: Reduction of central-line associated bloodstream infections in a tertiary care hospital in Saudi Arabia
}

\author{
WA Mazi ${ }^{*}$, Z Bejum', D Abdulmutalib', A Hisham², S Maghari², M Al Thumali², A Senok ${ }^{3}$ \\ From 2nd International Conference on Prevention and Infection Control (ICPIC 2013) \\ Geneva, Switzerland. 25-28 June 2013
}

\section{Introduction}

Central line-associated bloodstream infection (CLABSI) remains a major problem in critical care units worldwide.

\section{Objectives}

This study aimed to assess the impact of the implementation the Society for Healthcare Epidemiology of America/ Infectious Diseases Society of America (SHEA/ IDSA) practice recommendations in reducing CLABSI rates in an acute trauma intensive care unit (ICU).

\section{Methods}

The prospective study was conducted from January 2011-December 2012 at the 23-bed trauma-ICU in King Abdul Aziz Specialist Hospital, Taif, Saudi Arabia. In 2011, baseline data on CLABSI rates was collected. In 2012, a CLABSI-Team was established and the basic SHEA/IDSA practice recommendations implemented. Laboratory-confirmed CLABSI were identified using the Centers for Disease Control and Prevention criteria and antimicrobial susceptibility of isolates determined. For benchmarking with National Healthcare Safety Network (NHSN, USA), data collection and analysis were carried out in accordance with NHSN recommendations.

\section{Results}

With implementation of the SHEA/IDSA practice recommendations, a decline in the number of CLABSI in $2012(n=6)$ compared to $2011(n=14)$ was observed. This corresponds to a 58\% decline in CLABSI incidence rate from 3.87 to 1.5 per 1000 central-line days in 2011 and 2012 respectively (Standardized Infection Ratio, 0.42). Benchmarking to NHSN percentiles, the incidence of CLABSI was $75^{\text {th }}-90^{\text {th }}$ percentile in 2011 vs. $50^{\text {th }}$ percentile in 2012. The utilization ratio was $25^{\text {th }}-50^{\text {th }}$ percentile in 2011 and $50^{\text {th }}-75^{\text {th }}$ percentile in 2012. Three Klebsiella pneumoniae isolates susceptible only to imipenem and one pan-drug resistant Acinetobacter baumanii were identified in 2012. Two patients had Enterococcus faecalis, with one isolate resistant to vancomycin.

\section{Conclusion}

Implementation of the basic SHEA/IDSA practice recommendations resulted in significant reduction in CLABSI in our trauma-ICU where multidrug resistant isolates are present indicative of the beneficial role of these recommendations.

\section{Disclosure of interest}

None declared.

\section{Author details}

${ }^{1}$ infection prevention and control, Saudi Arabia. ${ }^{2}$ Intensive Care Unit, King Abdul Aziz Specialist Hospital, Taif, Saudi Arabia. ${ }^{3}$ College of Medicine, Alfaisal University, Riyadh, Saudi Arabia.

Published: 20 June 2013

doi:10.1186/2047-2994-2-S1-060

Cite this article as: Mazi et al:: O060: Reduction of central-line associated bloodstream infections in a tertiary care hospital in

Saudi Arabia. Antimicrobial Resistance and Infection Control 2013 2(Suppl 1): O60.

${ }^{1}$ infection prevention and control, Saudi Arabia

Full list of author information is available at the end of the article

(c) 2013 Mazi et al; licensee BioMed Central Ltd. This is an Open Access article distributed under the terms of the Creative Commons 